Louise Tofft*, Anders Telle Hoel, Carita Håkansson, Antoni Zawadzki, Helene Gjone, Tom Øresland, Kristin Bjørnland and Pernilla Stenström

\title{
Key components of successful transition for adolescents born with anorectal malformations-a Nordic focus group study
}

https://doi.org/10.1515/ijamh-2020-0052

Received March 18, 2020; accepted May 28, 2020;

published online September 4, 2020

\section{Abstract}

Objectives: Transitional care for adolescents with congenital malformations, such as anorectal malformations (ARM), is described sparsely in the literature and referred to as being inadequate. In order to organize future successful healthcare structures, knowledge of patientreported important aspects of transition is required. The aim of the study was therefore to explore the needs and expectations of transitional- and adult healthcare among adolescents and adults born with ARM.

Methods: Two tertiary paediatric surgical centres, in collaboration with two tertiary pelvic floor centres, in Sweden and Norway, conducted a qualitative study, involving adolescents and adults born with ARM in focus

*Corresponding author: Louise Tofft, MD, Department of Paediatric Surgery, Skåne University Hospital and Department of Clinical Sciences, Paediatrics, Lund University, S-221 85 Lund, Sweden, E-mail: louise.tofft@med.lu.se, Phone: +46 46177977.

https://orcid.org/0000-0001-5663-035X (L. Tofft)

Anders Telle Hoel and Kristin Bjørnland, Department of Paediatric Surgery, Oslo University Hospital and University of Oslo, Oslo, Norway, E-mail: andho@ous-hf.no (A.T. Hoel),

kristin.bjornland@medisin.uio.no (K. Bjørnland)

Carita Håkansson, Division of Occupational and Environmental Medicine, Lund University, Lund, Sweden,

E-mail: carita.hakansson@med.lu.se

Antoni Zawadzki, Department of Surgery, Pelvic Floor Centre Malmö, Skåne University Hospital and Lund University, Malmö, Sweden,

E-mail: antoni.zawadzki@skane.se

Helene Gjone, Division of Paediatric and Adolescent Medicine, Department of Child and Adolescent Mental Health in Hospitals, Oslo University Hospital, Oslo, Norway, E-mail: hegjon@ous-hf.no

Tom Øresland, Pelvic Floor Centre, Department of GI Surgery, Akershus University Hospital and University of Oslo, Oslo, Norway, E-mail: tom.oresland@medisin.uio.no

Pernilla Stenström, Department of Paediatric Surgery, Skåne University Hospital and Department of Clinical Sciences, Paediatrics, Lund University, Lund, Sweden,

E-mail: pernilla.stenstrom@med.lu.se group discussions regarding transitional care. Discussions were analyzed by qualitative content analysis. Ethical approval was obtained.

Results: Sixteen participants (10 women) with a median age of 24 (19-47) years, born with mixed subtypes of ARM were included in gender-divided focus groups. Participants emphasized a need for improved knowledge of ARM, both among patients and adult care providers. Participants identified a need for support with coping strategies regarding challenging social- and intimate situations due to impaired bowel function. Participants pin-pointed wellfunctioning communication between the patient and the paediatric- and adult care providers as a key factor for a successful transitional process. Further, participants emphasized the importance of easy access to specialized adult healthcare when needed, suggested to be facilitated by appointed patient navigators.

Conclusion: Adolescents and adults born with ARM identify improved knowledge of ARM, well-functioning communication and easy access to specialized adult care as key components of a successful transition.

Keywords: anorectal malformations; focus groups; health literacy; patient involvement; transition.

\section{Introduction}

Affecting one in 4,000 live births, anorectal malformations (ARM), also known as anal atresia, constitute a spectrum of congenital malformations involving the hind gut and pelvic floor [1, 2]. Children born with ARM undergo surgical reconstruction through posterior sagittal anorectal plasty (PSARP) [3]. As a result of the nature of ARM, possible concomitant malformations of the spine, urinary- and genital tract (and sometimes because of surgical damage), functional sequelae, such as faecal incontinence and impaired urinary tract- and sexual function, may remain throughout life [4-7]. Depression and other psychological disorders also seem to be frequent among adults born with ARM $[4,8]$. Long-term outcome in ARM is reported to be influenced by the type of ARM, concomitant 
malformations, type of reconstructive surgery and coping strategies [9-14].

Since patients born with ARM might suffer from several somatic- and psychological conditions related to their congenital malformation, they depend on life-long treatment and follow-up by multiple medical specialties. There are a few studies exploring the transitional process from paediatric- to adult healthcare for patients born with ARM [15-19]. The transitional care is referred to as being inadequate, but the manner in which adolescents wish to make their transfer has not yet been explored.

In order to design a successful transition for adolescents born with ARM, knowledge of their needs and expectations of the healthcare system is required. Therefore, the aim of this study was to explore needs and expectations of transitional- and adult healthcare among adolescents and adults born with ARM.

\section{Materials and methods}

The study was a qualitative study conducted at two tertiary centres of paediatric surgery, in collaboration with two tertiary pelvic floor centres, in Sweden and Norway. Data were derived from focus group discussions [20] with adolescents and adults born with ARM and analyzed through qualitative content analysis [21].

\section{Data collection}

Adolescents and adults born with ARM and formerly treated at these two centres of paediatric surgery were identified through hospital records. Patients with syndromes, predominately trisomy 21 , and patients living more than a 3-h car drive away were excluded. Eligible patients were invited and informed by postal letters. Participants did not receive any financial compensation.

Data were collected through gender-divided focus group discussions between January and August 2018. In line with the original method [20, 22], focus group discussions were led by one researcher at each centre, acting as a discussion moderator, accompanied by one or two silent observers taking notes. The moderators initiated discussion topics on previously known issues and challenges that might arise for people born with ARM $[4-6,9,23]$ through semi-structured openended questions (Appendix 1) and fictional case stories, so-called vignettes [24] (Appendix 2) for discussion enhancement. Discussions were audio recorded and transcribed verbatim with removal of personal data.

\section{Data analysis}

Data analysis was performed through qualitative content analysis: on both a manifest level; what was described directly by the participants, and on a latent level; the underlying meaning that was perceived by the authors $[21,25]$. The transcribed material was read through to grasp the overall meaning. Meaning units were then identified and condensed, where text volume was compressed without loss of content. Condensed meaning units were coded and grouped into subcategories. According to the content, sub-categories merged into categories. From categories an overall theme emerged. The process involved continuous comparison to transcribed text, discussion and adjustment of categorization before the authors could agree on the final result. Examples of the analysis process, the so-called audit trail, are displayed in Table 1.

Qualitative research criteria for reaching trustworthiness [26] were applied. Credibility was ensured by data collection from multiple focus groups, by requesting participants' immediate feedback during and after focus group discussions and by involving several researchers in the analyzing process. Transferability was ensured by thorough description of the strategic sampling method and the results. Dependability was ensured by a constant comparison and connection to raw data during analysis. Confirmability was ensured by maintaining a continuous discussion between researchers during data collection and analysis, and a transparent description of the analysis steps in the so-called audit trail.

\section{Ethics}

The study was approved by the Regional Ethical Review Boards at both institutions (2017/867, 2017/1895). Eligible patients received written information of the study. Participants received additional oral information and gave written consent. They were informed of the possibility of participation withdrawal at any time without stated cause or

Table 1: Audit trail: examples of meaning units, condensed meaning units, sub-categories and categories from the content analysis.

\begin{tabular}{|c|c|c|c|}
\hline Meaning unit & Condensed meaning unit & Sub-category & Category \\
\hline $\begin{array}{l}\text { 'You know that something' wrong but you don't } \\
\text { know what it is.' }\end{array}$ & $\begin{array}{l}\text { Participants lacked knowledge of } \\
\text { their condition }\end{array}$ & $\begin{array}{l}\text { Patient } \\
\text { education }\end{array}$ & Improved knowledge of ARM \\
\hline $\begin{array}{l}\text { 'It's been great attending such gatherings and meet } \\
\text { people who have the same challenges as your- } \\
\text { self and be able to be } 100 \% \text { yourself.' }\end{array}$ & $\begin{array}{l}\text { Patient associations were } \\
\text { described as valuable sources of } \\
\text { support and information }\end{array}$ & $\begin{array}{l}\text { Patient } \\
\text { associations }\end{array}$ & Improved knowledge of ARM \\
\hline $\begin{array}{l}\text { 'It has affected my intimate life. It took years before } \\
\text { I dared involve myself intimately.' }\end{array}$ & $\begin{array}{l}\text { The condition affected intimate re- } \\
\text { lationships negatively }\end{array}$ & $\begin{array}{l}\text { Intimate } \\
\quad \text { relationships }\end{array}$ & Support with coping strategies \\
\hline $\begin{array}{l}\text { 'It would have been great to have a person who } \\
\text { could inform your new doctors, so they got the } \\
\text { correct information and got involved right away.' }\end{array}$ & $\begin{array}{l}\text { Transitional meetings with paedi- } \\
\text { atric- and adult care givers were } \\
\text { warranted }\end{array}$ & & $\begin{array}{l}\text { Communication between the pa- } \\
\text { tient and paediatric- and adult } \\
\text { care providers }\end{array}$ \\
\hline
\end{tabular}


impact on future healthcare. They were also offered optional individual counselling outside the study.

\section{Results}

\section{Participants}

Four gender-divided focus groups, one female and one male focus group in each country, were formed by a total of 16 participants with eight participants (five women and three men) from each country (Figure 1). Sixty three percent of the participants were born with more severe types of ARM. All had reconstructive surgery with PSARP and $81 \%$ had a colostomy as neonates. All stomas had been closed after the PSARP in childhood, and none of the participants had a colostomy later nor at the time of the study. At present time, 44\% used an appendicostomy for bowel irrigation, predominately for faecal incontinence therapy (Table 2). Fifty percent had had prior contact with a pelvic floor center.

\section{Analysis of focus group discussions}

Focus group discussions lasted between 60 and $120 \mathrm{~min}$ each. Participants discussed the consequences of being born with ARM and their experiences of transitional- and adult healthcare, which often had failed to meet their needs and expectations.

Participants expressed a desired feeling of normality, constituting the emerged overall theme of the focus group discussions.

Participants identified improved knowledge of ARM, support with coping strategies for managing a chronic condition, well-functioning and feasible communication between the patient and care providers during transition, and easy access to specialized adult healthcare when needed, as key components of a successful transition (Figure 2).
Table 2: Description of participants born with anorectal malformations (ARM).

\begin{tabular}{|c|c|c|c|c|}
\hline Participants & & $\begin{array}{l}\text { Total } \\
n=16\end{array}$ & $\begin{array}{r}\text { Women } \\
n=10\end{array}$ & $\begin{array}{l}\text { Men } \\
n=6\end{array}$ \\
\hline $\begin{array}{l}\text { Age median } \\
\text { years } \\
\text { (range) }\end{array}$ & & $\begin{array}{r}24(19- \\
47)\end{array}$ & $\begin{array}{r}23(19- \\
45)\end{array}$ & $\begin{array}{r}24(19- \\
47)\end{array}$ \\
\hline \multirow[t]{7}{*}{ Type of ARM } & Perineal fistula & & 3 & \\
\hline & Vestibular fistula & & 1 & \\
\hline & Cloaca & & 5 & \\
\hline & Cloacal exstrophy & & 1 & \\
\hline & Recto-urethral fistula & & & 3 \\
\hline & $\begin{array}{l}\text { Recto-bladder } \\
\text { neck fistula }\end{array}$ & & & 1 \\
\hline & Unknown & & & 2 \\
\hline \multirow[t]{2}{*}{ Stomas } & Neonatal colostomy & 13 & 7 & 6 \\
\hline & $\begin{array}{l}\text { Present } \\
\text { appendicostomy }\end{array}$ & 7 & 4 & 3 \\
\hline
\end{tabular}

\section{Improved knowledge of ARM}

Participants underlined their present lack of knowledge of their condition, as well as the generally low level of knowledge of ARM in adult healthcare.

\section{Patient education}

Many participants expressed a wish for improved knowledge and understanding of their condition regarding, e.g. bowel function, fertility and genetics. They described knowledge as a way to empowerment. Some had searched for accurate information but encountered difficulties in retrieving it. Participants therefore suggested that patients should be offered individually adapted education from an early age by healthcare providers, through written materials, films, and individual- or group meetings. Valid institutional specific information through the hospitals'

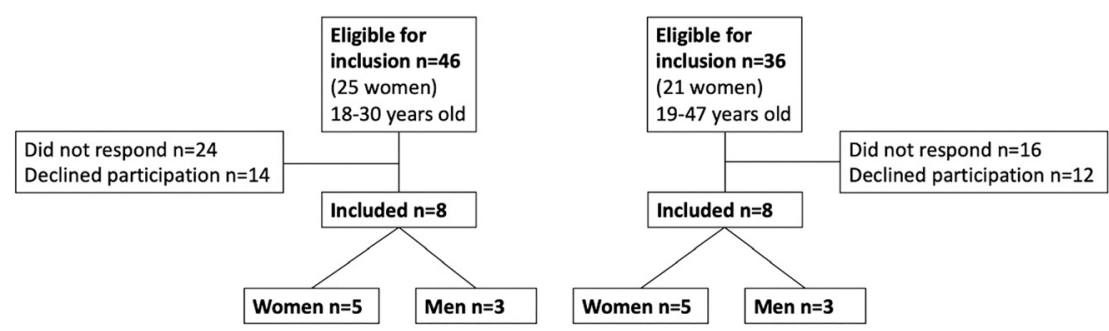

Figure 1: Inclusion chart of participants born with anorectal malformations (ARM). 


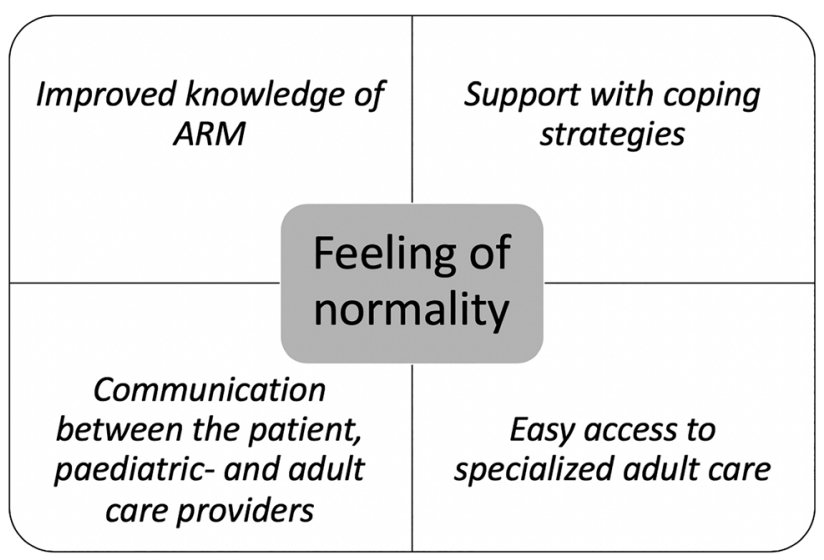

Figure 2: Key components of successful transition for adolescents born with anorectal malformations (ARM).

official digital channels was suggested to contribute to and improve information available online.

'I know very little [about the condition]. In childhood I was only informed in a "doctor's language" by the doctors, and I just tuned out then ... It's hard to find out stuff later when you're grown up.' (Participant M)

'I googled ... Foolish thing to do! I almost started to cry. It was a lot of information, I didn't recognize everything but how people write online! It sounded awful! Please give me some real information before I start to read [online]!' (Participant $\mathrm{H}$ )

\section{Patient associations}

Norwegian participants described the importance of their ARM-patient association regarding support and information. Swedish participants expressed a wish for a patient association. Some revealed that taking part in this study was the first time they had ever met other people born with ARM. Social media was described by some participants as an important forum of support and information. Some participants suggested peer-to-peer mentoring.

'I've been to some gatherings with the patient association. It's great to be at such meetings. You meet people with the same challenges as yourself.' (Participant L)

'I would have liked a contact person, with the same condition as me, perhaps 10 years older than me ... That would have been valuable for me. Someone you could contact through your doctor.' (Participant A)

'Group meetings with people of the same age, that would have been interesting.' (Participant D).

\section{Adult healthcare competence}

Participants described a hopelessness and powerlessness when they had tried in vain to obtain adequate adult care. They gave several examples where various adult care providers had shown a lack of knowledge of ARM. This was described as a major reason for participants not getting the help that they needed. Female participants gave examples of not being taken seriously or not being believed by care providers in gynaecology-, surgery- and urology departments.

In contrast, the specialized pelvic floor centres were described by participants in both countries as good examples of competent and respectful adult care.

\footnotetext{
'You are at the hospital, and you try to explain: "I have anal atresia", and they have no idea what it is, and they ask all kinds of degrading questions, and they want ME to know why I have my problems, and I mean that's why I'm here so that YOU can offer me help! ... Somewhere along the way I've just given up.'(Participant I)

'I agree! You call one nurse, and she says: I'll connect you. And then you talk to another one. And soon you've explained your problem over the phone to five different strangers. You feel completely worthless.' (Participant G)

'It's been the centre of pelvic floor conditions that has been the best so far. The one [physician] I got now is completely amazing.' (Participant H)
}

\section{Support with coping strategies}

Participants discussed several situations, where consequences of ARM, e.g. faecal- or gas leakage, prolonged toilet visits or sudden abdominal pain, were described as limiting for their everyday life. Strategies for handling embarrassing leak situations, taking part in social activities and experiencing security in intimate relations were discussed. Instead of only focusing on treatment of physical symptoms, which participants often seemed to have accepted, participants emphasized the importance of support to achieve positive coping strategies when living with a chronic condition such as ARM and thus attain a feeling of normality.

\section{Bowel function}

Participants described their need to adapt and restrict their lives due to extended and frequent visits to the bathroom, fear of faecal leakage and embarrassing 
flatulence. Participants disclosed that they needed a bathroom close by, and sometimes avoided sport activities or travel. Some experienced repeated severe stomach pains, sick leave from work and visits to the emergency room. Participants stated various needs of bowel management: from no treatment to bowel irrigation through an appendicostomy. Routines, food and stress were described to influence their bowel function. Some described their teens to be the worst period to be living with a dysfunctional bowel disorder, but coping abilities had improved thereafter.

'You constantly ask yourself: Where is the nearest bathroom?' (Participant C)

'I have played a lot of football, but sometimes, when you suddenly have the urge to go to the bathroom, it's like: Oh no, now it happened ...' (Participant A)

'I have always been passive when it comes to sport activities.' (Participant C)

'You've developed some kind of strategy system, how to plan your day to make it work. You take care of "business" before you go out.' (Participant D)

'I feel that the [bowel] function has improved with age ... maybe I take the signals [from the bowel] a little more seriously now and I go to the bathroom when I have to.' (Participant J)

\section{Intimate relationships}

Participants highlighted the importance of having a satisfactory sex life but described that their malformation sometimes made intimate situations challenging regarding, e.g. faecal leakage and flatulence. Some male participants discussed impotence problems and various coping strategies in dealing with them such as using humour as a diversion. Participants seemed to prefer longterm relationships, avoiding casual sexual contacts. They expressed a need for substantial trust with their partners. Some female participants described a great effort in hiding their condition.

'I think about these [sexual] issues a lot. It's an uncertainty in my everyday life. How should I cope?!' (Participant I)

'I think it's such an unsexy thing!! And who wants to have unsexy sex?!' (Participant H)

'I take care of my condition, Inever let it happen [faecal leakage] ... but I would never tell my boyfriend! Perhaps my future husband.' (Participant G)

\section{Social- and professional life}

Participants expressed the importance of trust towards friends, employers and colleagues. The closest family members seemed to be the only secure circle of trust for some female participants. Some said that telling their employers made their working life easier. Some concluded that being born with ARM had contributed to their choices of profession, using their personal experiences to help others. Many emphasized the importance of having an occupation that allowed flexibility and mobility.

Some participants shared painful experiences of being victims of bullying during their school-days due to, e.g. faecal- and urinary incontinence.

Postoperative scars seemed to have a significant impact. Some described a hatred towards their scarring. Participants gave examples of immodest stares and rude comments from others. Different coping strategies were discussed, such as keeping covering clothes on at the beach.

'You can always give your employer another explanation, maybe say that my back is better if I stand up working.' (Participant E)

'Yes. You don't have to lie, just tell them that you feel better if you move around ... If you don't have a lot of problems you don't have to tell your employer.' (Participant $\mathrm{H})$

'Yes. And you can always blame it on something else. Like your period. Blaming stuff on your period is in my experience an effective way to stop especially guys from asking questions!' (Participant E)

'It was hard when I was a teenager, showing myself at the beach for example, showing my rather ugly scar, it's not a pretty scarring, my stomach is quite deformed.' (Participant $\mathrm{C}$ )

\section{Communication between the patient and paediatric- and adult care providers}

Participants described a present inadequate transition from paediatric- to adult care, primarily due to a nonexisting communication between the patient and paediatric- and adult care providers. Participants emphasized a need for an individually adapted transitional process, designed by the patient and healthcare providers together. A well-functioning and feasible communication between all parties was identified as a key component of transitional care. Participants highlighted the necessity of taking the adolescent's individual maturation into account, letting the transition occur when the patient was ready for it instead of having a fixed transitional age. Participants called for dedicated, supportive physicians taking 
responsibility for the transitional process. Many declared the pelvic floor centres to be good examples of providing satisfactory adult care and argued the case for these centres to be referral centres of choice.

'They all [adult care providers] look like question marks.'(Participant C)

'We want some kind of transitional reporting.' (Participant D)

'But you have to conduct this meeting when the person is ready for it ... I think you should have this talk later at the pelvic floor centre. The paediatric surgeon could come there.' (Participant $\mathrm{C}$ )

\section{Easy access to specialized adult care}

Participants described a non-supportive and nonreachable adult healthcare system, difficult to get through to when participants had tried. Participants expressed a need for more accessible specialized adult care when in need of it.

\section{Patient navigator}

A few participants had had transitional meetings, but maintaining contact with all of the different adult medical specialities was described as difficult. Participants called for an appointed patient navigator, e.g. a specialized nurse, to assist in organizing appointments with required medical specialities and counselling patients regarding medical enquiries.

'It should be some kind of coordinator who knows what it is about.' (Participant G)

\section{Discussion}

This qualitative focus group study involving adolescent and adult ARM-patients identified knowledge of ARM, support with coping strategies, well-functioning and feasible communication between patients and care providers, and easy access to specialized adult care as key components of adequate transitional care. Findings of this study suggest several essential clinical implications for improving transition.

Firstly, patient education and patient health literacy were described as important, which is in line with previous studies regarding the transition to adult care for patients with chronic conditions [17, 27-30]. Knowledge and condition literacy are also reported to be essential contributors to positive coping abilities when living with a chronic condition [31, 32]. Findings in this study indicate a need for a larger pedagogical effort from healthcare providers. These desired educational settings should preferably start, according to participants in this study, at the paediatric surgery departments when patients are young, and continue into adulthood. This study also identified the need for updated and customized patient information materials available online, where examples from leading paediatric surgery departments in the US may serve as inspiration [33, 34].

Secondly, the importance of a structured, individually adapted transitional process for ARM-patients previously identified by other studies $[15,17]$ was confirmed by this study. Participants emphasized the importance of a dynamic transitional process, grounded in the individual's needs and wishes by e.g. adapting the time for transition according to the individual's degree of maturation and social situation. Participants in our study advocated the pelvic floor centres to be referral centres of choice in the transitional process of ARM-patients. Since ARM-patients often suffer from several malformations and associated problems in the gastrointestinal-, urinary- and genital tract [2], one could argue that specialized centres including all of these adult medical specialties would offer the best healthcare for rare and challenging conditions such as ARM.

Thirdly, participants in this study called for supporting patient navigators. As highlighted previously, patient navigators seem to provide higher patient satisfaction for patients in need of continuous contact with healthcare providers [27].

Strengths of this study include a broad inclusion population from two countries and formation of multiple, slightly heterogenous focus groups. By using focus groups, we identified crucial aspects of transitional care from the patients' perspectives. The qualitative analysis gave us an understanding of which components of transition that patients think are important. This is a strength compared to using pre-defined items in a quantitative questionnaire. Previous studies have shown utilization of patients' unique insights provides research with greater validity and gives valuable input for future research topics $[35,36]$.

A possible weakness of this study was the two-centre approach with two different discussion moderators. This might have influenced the results both in a positive way, by including broader aspects and diverse reflections, but also in a negative way by reducing consistency. The attending rate was quite low which could be explained by the lack of financial compensation and the intimate nature of topics discussed in the focus groups.

Looking ahead, findings of this study imply further research in genetics, sexual function and fertility, 
consequences and management of postoperative scarring, and homogenous clinical transition programmes for ARM.

In conclusion, adolescents and adults born with ARM identify knowledge of ARM, well-functioning and feasible communication between patient and care providers, and easy access to specialized adult care as main key components of a successful transition. Our findings highlight the importance of patient involvement to organize future healthcare structures.

Acknowledgments: Sara Johnsdotter, PhD Professor, Institution of Health and Society, Malmö University, Sweden, for introducing the idea of exploring adolescents' needs through focus group discussions. Annette Mörk, midwife and sexologist, and Karolina Savik, social worker and sexologist, Institution of Health and Society, Malmö University, Sweden, for moderating and transcribing focus group discussions in Lund. Svein Staff and Catherine Plancke, Department of Surgery, Pelvic Floor Center Akershus, Oslo University, Norway, for moderating focus group discussions in Oslo.The study was presented as a poster at the EUPSA (European Paediatric Surgeons' Association) Congress in Belgrade, Serbia 2019 and as an oral presentation at the Swedish Surgical Society Congress "Kirurgveckan" in Norrköping, Sweden 2019.

Research funding: This research did not receive any specific grant from funding agencies in the public, commercial, or not-for-profit sectors.

Ethical approval: The study was approved by the Regional Ethical Review Boards at both institutions (2017/867, 2017/ 1895).

Author contributions: All authors have accepted responsibility for the entire content of this manuscript and approved its submission.

Competing interests: Authors declare no conflicts of interest.

Informed consent: Informed consent was obtained from all individuals included in this study.

\section{References}

1. Svenningsson A, Gunnarsdottir A, Wester T. Maternal risk factors and perinatal characteristics of anorectal malformations. J Pediatr Surg 2018;53:2183-8.

2. Levitt MA, Peña A. Anorectal malformations. Orphanet J Rare Dis 2007;2:33.

3. Peña A, Devries PA. Posterior sagittal anorectoplasty: important technical considerations and new applications. J Pediatr Surg 1982;17:796-811.
4. Danielson J, Karlbom U, Graf W, Wester T. Outcome in adults with anorectal malformations in relation to modern classificationwhich patients do we need to follow beyond childhood? J Pediatr Surg 2017;52:463-8.

5. Stenström P, Kockum CC, Benér DK, Ivarsson C, Arnbjörnsson E. Adolescents with anorectal malformation: physical outcome, sexual health and quality of life. Int J Adolesc Med Health 2014; 26:49-59.

6. Kyrklund K, Pakarinen MP, Rintala RJ. Long-term bowel function, quality of life and sexual function in patients with anorectal malformations treated during the PSARP era. Semin Pediatr Surg 2017;197:1363-5.

7. Vilanova-Sanchez A, Reck CA, McCracken KA, Lane VA, Gasior AC, Wood RJ, et al. Gynecologic anatomic abnormalities following anorectal malformations repair. J Pediatr Surg 2018; 53:698-703.

8. Grano C, Bucci S, Aminoff D, Lucidi F, Violani C. Feelings of depression in people with ARM: the role of critical incidents and perceived difficulties in close and sexual relationships. Pediatr Surg Int 2014;30:823-8.

9. van den Hondel D, Sloots CEJ, Bolt JM, Wijnen RMH, de Blaauw I, IJsselstijn H. Psychosexual well-being after childhood surgery for anorectal malformation or Hirschsprung's disease. J Sex Med 2015;12:1616-25.

10. Kyrklund K, Taskinen S, Rintala RJ, Pakarinen MP. Sexual function, fertility and quality of life after modern treatment of anorectal malformations. J Urol 2016;197: 1363-5.

11. Grano C, Bucci S, Aminoff D, Lucidi F, Violani C. Transition from childhood to adolescence: quality of life changes 6 years later in patients born with anorectal malformations. Pediatr Surg Int 2015;31:735-40.

12. Springford LR, Connor MJ, Jones K, Kapetanakis VV, Giuliani S. Prevalence of active long-term problems in patients with anorectal malformations: a systematic review. Dis Colon Rectum 2016;59:570-80.

13. Rintala RJ. Congenital cloaca: long-term follow-up results with emphasis on outcomes beyond childhood. Semin Pediatr Surg 2016;25:112-6.

14. Grano C, Fernandes M, Aminoff D, Bucci S, Lucidi F, Violani C. The role of coping strategies on health-related quality of life in adults with anorectal malformations. Pediatr Surg Int 2016;32:759-65.

15. Cairo SB, Gasior A, Rollins MD, Rothstein DH. Challenges in transition of care for patients with anorectal malformations: a systematic review and recommendations for comprehensive care. Dis Colon Rectum 2018;61:390-9.

16. Cairo SB, Chiu PPL, Dasgupta R, Diefenbach KA, Goldstein AM, Hamilton NA, et al. Transitions in care from pediatric to adult general surgery: evaluating an unmet need for patients with anorectal malformation and Hirschsprung disease. J Pediatr Surg 2018;53:1566-72

17. Giuliani S, Grano C, Aminoff D, Schwarzer N, Van De Vorle M, Cretolle $C$, et al. ARM-net Consortium. Transition of care in patients with anorectal malformations: consensus by the ARM-net consortium. J Pediatr Surg 2017;52:1866-72.

18. Muise ED, Cowles RA. Transition of care in pediatric surgical patients with complex gastrointestinal disease. Semin Pediatr Surg 2015;24:65-8.

19. Witvliet MJ, Petersen N, Ekkerman E, Sleeboom C, van Heurn E, van der Steeg AFW. Transitional health care for patients with 
Hirschsprung disease and anorectal malformations. Tech Coloproctol 2017;21:547-54.

20. Krueger RA, Casey MA. Focus groups-a practical guide for applied research, 5th ed. SAGE Publications Inc., Los Angeles, CA, US; 2015. https://doi.org/10.1002/j.1556-6678.2007.tb00462.x.

21. Graneheim UH, Lundman B. Qualitative content analysis in nursing research: concepts, procedures and measures to achieve trustworthiness. Nurse Educ Today 2004;24:105-12.

22. Dahlin-Ivanoff FS, Holmgren K. Fokusgrupper, 1st ed. Studentlitteratur Lund Sweden; 2017. ISBN: 9789144101132.

23. Konuma K, Fukumoto H, Masuyama H, Okamoto S, Masuyama H, Fukumoto H. Sexual problems in male patients older than 20 years with anorectal malformations. J Pediatr Surg 2006;41: 306-9.

24. Barter C, Renold E. I wanna tell you a story: exploring the application of vignettes in qualitative research with children and young people. Int J Soc Res Methodol 2000;3:307-23.

25. Graneheim UH, Lindgren BM, Lundman B. Methodological challenges in qualitative content analysis: a discussion paper. Nurse Educ Today 2017;56:29-34.

26. Frambach JM, Vleuten CPM, Durning SJ. Quality criteria in qualitative and quantitative research. Acad Med Am J Occup Ther BMJ 2013;88:552.

27. McBrien KA, Ivers N, Barnieh L, Bailey JJ, Lorenzetti DL, Nicholas $D$, et al. Patient navigators for people with chronic disease: a systematic review. PLoS One 2018;13:e0191980.

28. Bomba F, Herrmann-Garitz C, Schmidt J, Schmidt S, Thyen U. An assessment of the experiences and needs of adolescents with chronic conditions in transitional care: a qualitative study to develop a patient education programme. Health Soc Care Community 2017;25:652-66.
29. McCracken KA, Fallat ME. Transition from pediatric to adult surgery care for patients with disorders of sexual development. Semin Pediatr Surg 2015;24:88-92.

30. Kyngäs H. Patient education: perspective of adolescents with a chronic disease. J Clin Nurs 2003;12:744-51.

31. MacKey LM, Doody C, Werner EL, Fullen B. Self-management skills in chronic disease management: what role does health literacy have? Med Decis Making 2016;36:741-59.

32. Heijmans M, Waverijn G, Rademakers J, van der Vaart R, Rijken M. Functional, communicative and critical health literacy of chronic disease patients and their importance for self-management. Patient Educ Couns 2015;98:41-8.

33. International Center for Colorectal and Urogenital Care. Available from: https://www.childrenscolorado.org/doctorsand-departments/departments/colorectal/ [Accessed 3 Oct 2019].

34. Colorectal Center Cincinnatti Childrens Hospital. Available from: https://www.cincinnatichildrens.org/service/c/colorectal/ conditions-treated/anorectal-malformations [Accessed 3 Oct 2019].

35. Price A, Albarqouni L, Kirkpatrick J, Clarke M, Liew SM, Roberts N, et al. Patient and public involvement in the design of clinical trials: an overview of systematic reviews. J Eval Clin Pract 2018; 24:240-53.

36. Bate J, Ranasinghe N, Ling R, Preston J, Nightingale R, Denegri S. Public and patient involvement in paediatric research. Arch Dis Child Educ Pract Ed 2016;101:158-61.

Supplementary material: The online version of this article offers supplementary material (https://doi.org/10.1515/ijamh_2020-0052). 